\title{
O cyberpunk ocidental e oriental: as distâncias textuais entre Blade Runner e Tetsuo
}

\section{North American and Japanese Cyberpunk: The Textual Distances between Blade Runner and Tetsuo}

\author{
Ricardo Jorge de Lucena Lucas ${ }^{1}$ \\ Lucas Bernardo Reis ${ }^{2}$
}

DOI: $10.19177 /$ memorare.v8e12021160-177

\begin{abstract}
Resumo: 0 presente artigo busca estudar as diferenciações entre o cyberpunk ocidental e oriental no cinema e nas artes visuais. Para isso, procuramos relações entre a história em quadrinhos "The Long Tomorrow" e o filme Blade Runner, e a arte ero-guro e o filme Tetsuo. Buscamos responder quais aspectos tornam essas obras particulares e distintas entre si. Para tal, revisitamos alguns preceitos canônicos do cyberpunk e de suas particularidades nas culturas norteamericana e japonesa a partir das influências transtextuais de algumas obras que lhes são anteriores. Os resultados parciais demonstraram que há cyberpunks distintos nesses países, mas que sofrem influências transtextuais de produções anteriores, e criam novos caminhos a partir dessa relação.
\end{abstract}

Palavras-chave: Cyberpunk. Blade Runner. Tetsuo.

\begin{abstract}
This article seeks to study the differences between Ocidental and Oriental cyberpunk in cinema and visual arts. For this, we look for relationships between the comic book "The Long Tomorrow" and the film Blade Runner, and the ero-guro art and the film Tetsuo. We seek to answer which aspects make these works private and distinct from each other. To this end, we revisit some canonical precepts of cyberpunk and its particularities in North American and Japanese cultures from the transtextual influences of some works that preceded them. The partial results demonstrated that there are distinct cyberpunks in these countries, but that suffer transtextual influences from previous productions, and create new paths based on this relationship. Keywords: Cyberpunk. Blade Runner. Tetsuo.
\end{abstract}

\footnotetext{
${ }^{1}$ Jornalista e professor do Programa de Pós-Graduação em Comunicação e do curso de Jornalismo do Instituto de Cultura e Arte da Universidade Federal do Ceará (ICA-UFC). ricardo.jorge@gmail.com

${ }^{2}$ Jornalista, mestre pelo Programa de Pós-Graduação em Comunicação do Instituto de Cultura e Arte da Universidade Federal do Ceará (ICA-UFC). lucasbernardoreis@gmail.com
} 


\section{Introdução}

A relevância do cyberpunk em nossa sociedade, a da informação, vai muito além de ideias ficcionais presentes nos livros; ela está nos estudos acadêmicos ou na comunidade de fãs da ficção científica que desenvolvem esse gênero literário, assim como na visão de mundo de uma sociedade em crescente contato com as tecnologias informáticas. Atualmente, cenários como os pandêmicos (Covid-19, variantes do Coronavírus etc.) e de forte expansão das práticas digitais (interações, transações comerciais) fazem com que olhemos para antigas obras "apocalípticas" com uma nova visão. No presente artigo, voltamos nossos olhares para duas obras tidas como clássicos cyberpunks, os filmes Blade Runner, o Caçador de Androides (Ridley Scott, 1982) e Tetsuo (Shinya Tsukamoto, 1989): apesar de serem produzidas em situações e culturas diferentes, ambas se colocam como integrantes desse subgênero pelas características que compartilham.

Cumpre lembrar que os dois filmes apresentam antecedentes estéticos distintos, quais sejam, respectivamente, a história em quadrinhos "The Long Tomorrow" (escrita por Dan O'Bannon e ilustrada por Jean Giraud, mais conhecido como Moebius, 1976) e as obras pertencentes à estética ero-guro-nansensu (surgida nos anos 1930). Ambas as influências podem ser vistas como uma espécie de proto-cyberpunk por terem acontecido antes da década de 1980, e, a nosso ver, essas influências ajudam a determinar, ao menos em parte, as diferenças conceituais sobre o cyberpunk nessas obras. Assim, quais aspectos estão presentes nessas obras que nos fazem pensá-las como obras cyberpunks? E quais aspectos as tornam particulares e distintas entre si, a partir dessas influências? Tais influências, obviamente, não esgotam a totalidade das relações transtextuais (GENETTE, 1982) possíveis entre os textos analisados e os textos que lhes são anteriores.

Para fins deste artigo, iniciamos com uma breve argumentação sobre a atualidade da discussão do conceito de cyberpunk; depois, analisamos rapidamente como alguns aspectos ligados ao cyberpunk estão presentes em alguns produtos culturais dos dois países; ao final, voltamos a nossa atenção tanto para os objetos de nossa análise quanto para os textos que os influenciaram de algum modo.

\section{Como pensar o cyberpunk hoje?}

As atuais discussões que buscam entender o cyberpunk, principalmente nos campos da Comunicação e das Ciências Sociais, abordam três momentos: seu nascimento na literatura; seu desenvolvimento na sociedade da informação; e como forma de compreensão do mundo no qual estamos imersos, cada vez mais pautado pela informação. Para fins deste artigo, consideramos o cyberpunk como intrinsecamente ligado ao contexto da década de 1980: conforme Kerckhove (1995), figuras como os yuppies foram substituídas pelos cyberpunks e a cultura da velocidade e do consumismo envolvia completamente as economias de mercado ocidentais. É nesse cenário e em meio à proliferação dos computadores pessoais e ao fluxo de informações crescente jamais visto que escritores e acadêmicos da 
nascente tecnologia da informação perceberam um fértil campo para os estudos e práticas literárias.

A relevância do cyberpunk fora de um nicho literário só foi iniciada em 1984, com a publicação da magnum opus de William Gibson, Neuromancer, no qual a palavra "ciberespaço" é vista também pela primeira vez, e com destaque para a relação entre a tecnologia da informação e um espaço permeado pelos processos de feedback e retroalimentação, conforme sugeridos pela Cibernética. Nessa obra, o cyberpunk tem suas premissas básicas estabelecidas ao combinar a realidade virtual e o estilo noir, como afirma Roberts (2018), também tendo na dicotomia entre o cult e o mainstream um importante fator de difusão como um subgênero da ficção científica. Dessa forma, é possível enxergar mudanças e a procura de novos caminhos da parte dos autores, na busca de um pensamento unificado entre literatura e as teorias sociais, trabalhando mais com as tecnologias da sociedade dos anos 1980 e colocando-se como uma representação da ascendente sociedade da informação.

É a partir disso que concordamos com Amaral sobre os anos 1980 definirem o cyberpunk e estarem intrinsecamente conectados com suas perspectivas estética e temática: esse subgênero é um produto definitivo daquela época, embora suas raízes estejam na tradição da ficção científica moderna popular, tanto da época dourada quanto da chamada New Wave, herdando temas, estéticas e estruturas narrativas de autores como autores como Philip K. Dick, fundamental para a existência de Blade Runner, e de filmes como Alphaville (Jean- Luc Godard, 1965), La Jetée (Chris Marker, 1962) e No Mundo de 2020 (Richard Feischer, 1973), tudo isso unido à cultura pop dos anos 80, seja rock, arte performática, cultura hacker e todas as manifestações artísticas underground (2006, p. 73).

Ademais, se quisermos pensar o cyberpunk hoje, é preciso enxergálo, conforme sugerem Gomes, Londero e Nascimento, além de um fato social, como um subgênero da ficção científica em meio a um "mundo globalizado e dominado pela desigualdade socioeconômica e, fundamentalmente, tecnológica" (GOMES, LONDERO \& NASCIMENTO, 2009, p. 111). Além disso, a relação do tema com as teorias da cibercultura embasa essa discussão, na medida em que "o cyberpunk é uma fonte para essas teorias, sendo estudado por diversos autores, quanto, na contramão, as teorias fundamentam cultural e socialmente esse tipo de ficção" (AMARAL, 2006, p. 41). Assim, o cyberpunk é tanto um subgênero da ficção científica quanto integrante de uma subcultura (AMARAL, 2006).

Jameson (1994, p. 188) fala sobre um realismo sujo que o cyberpunk e Blade Runner expandem. Segundo ele, essa ficção é "devotada aos detalhes locais, às nuances, às pequenas perturbações em linguagem e gesto [...] pessoas à deriva em um mundo atravancado por junk food e pelos detalhes opressores do consumismo moderno." Ele observa o cyberpunk em dois aspectos: I) continuação do naturalismo e II) representação do fim da sociedade. Naturalismo aqui é o que franceses chamavam de miserabilisme, no qual "as profundezas mais baixas, os espaços proibidos da nova cidade industrial, eram expostos a um público burguês horrorizado sob a forma de jornadas perigosas e o 
relato dos destinos patéticos das classes inferiores" (JAMESON, 1994, p. 192). 0 fim da sociedade seria indicado, de acordo com o autor, "pelo desaparecimento do espaço público enquanto tal: o fim do cívico e do governo oficial, que agora se dissolve em redes de corrupção e relações informais de clãs" (JAMESON, 1994, p.197).

Pensar o cyberpunk hoje é perceber como suas histórias e reflexões demonstram uma perspectiva pós-moderna de sociedade, em que a alteridade é deixada de lado, com o enfraquecimento da categoria "Outro". A diferença que era clara foi se tornando cada vez mais difícil de perceber, ocasionando, dessa forma, uma diluição de corpos e grupos. Ainda segundo Jameson (1994, p.193), "há uma circulação e recirculação possível entre o submundo e o mundo superior: cair deste último para o primeiro já não é mais um desastre tão absoluto e irrevogável, uma vez que isso oferece o conhecimento do que se costumava chamar de 'as ruas'”.

Os personagens também são pontos de reflexão importantes neste subgênero. Gomes, Londero e Nascimento (2009) afirmam que a literatura cyberpunk trabalha suas narrativas dos hackers aos mercenários, dos ciborgues aos sem corpo. No entanto, é a figura do andarilho, como "o pesquisador do infinito" (GOMES et al, 2009, p. 115), a mais recorrente no subgênero e a que mais o representa. Esse andarilho acaba transposto das estradas desérticas empoeiradas para o ciberespaço, em meio a uma aspiração medieval de vida eterna, na qual o corpo humano é desprezado para transformar-se em dados imateriais.

Assim, tratando as características do cyberpunk como uma atitude e um modelo de atuação próprios do século XXI, é possível apresentar o caráter ativista e libertador a ser perpetuado através das tecnologias. Isso demonstra que a temática vai muito além da figurativização e do escapismo literário tidos como tradicionais, na medida em que começa a desconstruir e a repensar a cultura tecnológica. Essa caminhada para longe do escapismo e da superficialidade que outros subgêneros da ficção científica podem apresentar faz com que o cyberpunk se coloque como uma cultura de contestação social, assim como uma atitude diante do uso desenfreado da tecnologia. Em suma, e conforme Lemos, "a atitude cyberpunk é, acima de tudo, um comportamento irreverente e criativo frente às novas tecnologias digitais" (2002, p.212), e isso nos fornece novos pensamentos e formas de enxergar o mundo para além da invasão da tecnologia em nosso cotidiano.

\subsection{O cyberpunk nas óticas oriental e ocidental}

O cyberpunk tende a seguir a mesma confluência da ficção científica, com elementos bastante variados e capacidade de se espalhar por diversas mídias. Seus temas e personagens são constantemente retrabalhados pois, assim como não deixam de nutrir e atrair sua comunidade de fãs, são uma forma compreensível de trabalhar temas inacessíveis junto ao grande público. Uma vez que trabalhamos com filmes e quadrinhos pensados em duas realidades geográficas e culturais diferentes, vamos discutir como suas diferenças tanto se aproximam do gênero quanto se afastam, criando duas modalidades possíveis de cyberpunk. 0 hiato de sete anos entre o lançamento de Blade Runner e Tetsuo, assim como as diferenças entre "The Long 
Tomorrow" e o eroguro, não ocasionam uma separação tão abrupta no entendimento dos dois filmes e dos temas abordados. Em se tratando dos filmes, ambos abordam a ficção científica cyberpunk tendo como uma das discussões centrais (para nós, talvez: o tema central) a questão do "corpo"3.

É perceptível também uma abordagem sobre o futuro a partir de reflexões do presente. No caso de Blade Runner, o tema "corpo" dos replicantes é margeado pelo futuro e vindouro (à época da produção do filme) caos populacional e informacional, que encontra uma âncora no mundo real a partir do aumento da presença de computadores pessoais nas residências americanas; Tetsuo, ao apresentar a sua narrativa no presente (também à época de sua produção), embasa-se na característica do pensamento oriental japonês para apresentar uma visão apocalíptica da chegada do século XXI. Nosso principal questionamento sobre as obras reside em quais seriam seus pontos de conexão, para entender como o cyberpunk trabalhado nas duas obras tem características distintas, apesar de ambas trabalharem com um mesmo tema.

Acreditamos que os pensamentos ocidental e oriental em que esses filmes foram produzidos e lançados podem nos oferecer respostas, graças ao modo peculiar dos dois pensarem a ficção científica. Falando especificamente da relação entre Japão e Estados Unidos, ressaltamos que essas duas sociedades compartilham informações, bens culturais e de consumo desde os anos de 1950, quando, logo após a explosão da bomba atômica nas cidades de Hiroshima e Nagasaki, os governos americanos comprometem-se a auxiliar os nipônicos em seu reerguimento financeiro e social. Esse processo, conhecido como "niponização" ou "japonização" (BORGES, 2016), é caracterizado pela absorção cultural americana por parte dos japoneses, principalmente na literatura e no cinema (MATTHEW, 2005). Essa aproximação também foi sentida em revistas, em quadrinhos, músicas, moda e pintura, influenciados massivamente pelo American Way of Life e ocasionando interessantes transformações culturais.

Essa adaptação cultural tornou o Japão um país peculiar: ao mesmo tempo em que mantém raízes fortes com suas tradições milenares, segue adicionando outras conexões a elas. Não à toa, Tóquio contrasta com seus arranha-céus, a movimentação veloz das pessoas, e os templos xintoístas e budistas incrustados em parques espalhados pela cidade. Perceber tal contraste é nossa primeira pista: na medida em que os japoneses prezam por seus ensinamentos mais antigos, até mesmo o cyberpunk, produto da cultura do computador e da pós-modernidade, sofre alterações substanciais, transformando-se em algo novo, ao menos aos olhares ocidentais.

A cultura americana da década de 1980, por sua vez, marcou o fortalecimento de um estilo de vida próprio. Logo após a Guerra do Vietnã e a crise do petróleo de 1970, os dez anos seguintes foram de transformação, evolução e divulgação de uma cultura de consumo e de mercado. A ficção científica aproveitou-se dessas emergências e adequou-se para uma nova abordagem, afastando-se das naves

\footnotetext{
${ }^{3}$ Essa discussão não será feita aqui por falta de espaço, mas tal aspecto será retomado em nossas considerações finais.
} 
espaciais e da psique dos personagens e focando justamente nessa cultura de mercado e de consumo envoltos pela tecnologia. Yuppies, computadores pessoais e o alvorecer da Internet podem representar esta década e, dessa forma, fazer parte das narrativas do seu período. Foram dessas influências que o movimento cyberpunk americano surgiu como subgênero literário de ficção científica, e espalhou seu pensamento por diversas formas de arte, do cinema à moda, da música à política.

Do outro lado do mundo, os japoneses, em meio à niponização, pensavam e viviam de forma diferente, o que afetava diretamente suas narrativas. Um ponto notório é a característica japonesa de pensar o mundo como um ciclo, um tempo em que tudo se renova e retorna eternamente para seu ponto inicial. Kato (2012) define esse estilo de narrativa como "aqui-agora", na qual o tempo presente e o espaço local de existência do indivíduo são sempre realçados em relação a uma narrativa que se desenrola para o futuro ou para o passado. É por isso $\left(\operatorname{cremos}^{4}\right)$ que a ficção científica cyberpunk japonesa não apresenta os cenários futuristas de maneira deslocada em relação a uma situação temporal do presente. Em Tetsuo, por exemplo, Tsukamoto faz com que os personagens não ajam em relação a acontecimentos que possam vir a decorrer de suas ações: seu pensamento está ligado à ação no presente, no ato de feitura e no exato local onde ela está acontecendo.

Essa diferença é bastante relevante se pensarmos que as produções de ficção científica americanas denotam quase sempre uma distopia, um futuro em que um modelo de sociedade foi malsucedido. Em Blade Runner é assim: a Los Angeles de 2019 coloca seres humanos oprimidos por arranha-céus infinitos. Se aqui temos o high tech, low life, no Japão temos o low tech, low life 5 . Como exemplo, além de Tetsuo, podemos citar alguns animes e/ou mangás japoneses conhecidos, como Akira, Ghost in the Shell, Alita, Serial Experiments Lain ou Ergo Proxy: todas eles discutem o cyberpunk a partir de objetos diferentes, mas tendo em comum a presentificação e a utilização do espaço local com uma forma de apresentação de suas narrativas. Passado e futuro não são relevantes aqui, apenas o momento atual em que as histórias acontecem. Suas histórias também abordam com frequência o cenário pós-apocalíptico de uma civilização que chegou a esse estágio por problemas próprios. Objetos, cenários abandonados, localidades vazias ou superpopulosas essa é uma visão tradicionalmente japonesa, ou seja, se a distopia é potencialmente futura na visão norte-americana, ela está potencialmente no presente, no aqui e agora do tempo-espaço japonês.

Outra diferença marcante no imaginário ocidental norte-americano é a presença do hacker. Produções audiovisuais como Matrix, 13ํAndar, Johnny Mnemonic: o cyborg do futuro, Mr. Robot, Anon, Black Mirror e Blade Runner discutem o cyberpunk a partir de objetos diferentes, mas encontram um ponto de contato no personagem central das histórias: o

4 Obviamente, isso pode ser tema de outra pesquisa: as representações cronotópicas na produção cyberpunk japonesa e se elas seriam ou não, por exemplo e conforme sugere Eco (1989, p. 171), narrativas para prevenir em relação a certas previsões futuristas, em vez de narrativas para prever e estimular tais acontecimentos.

${ }^{5}$ As expressões significam, respectivamente, "alta tecnologia, baixa qualidade de vida" e "baixa tecnologia, baixa qualidade de vida". 
hacker, que assume o papel de messias ou de detetive, personagem essencial do cyberpunk desenvolvido da história.

Apesar de ser possível enumerar outros aspectos importantes nas produções cyberpunk japonesas e norte-americanas, para fins deste artigo basta, por ora, apontar algumas das diferenças distinguíveis (corpo, tempo, personagem central) na produção cultural de ambos os países. Uma vez realizado este breve percurso, voltamo-nos agora para um olhar mais cuidadoso em relação a tais aspectos em nossos objetos de análise.

\subsection{Pausa: uma questão metodológica}

Apontamos inicialmente que nossa análise levaria em consideração o poder de influência de textos anteriores em Blade Runner e Tetsuo. De uma série de possibilidades intertextuais, adotamos (sem pretensão de finalizar o tema) a proposta engendrada por Genette (1982) de considerar, dentre os diferentes níveis transtextuais ${ }^{6}$ que sugere em sua obra, a hipertextualidade.

Por "hipertextualidade", Genette entende como a relação pela qual um texto de origem ("hipotexto") gera outra versão ("hipertexto") que pode ser de diversas naturezas: adaptação de um meio/suporte para outro, paródia, pastiche, sátira etc. Assim, de certo modo, toda obra seria derivada de outra obra anterior, por transformação ou por imitação (GENETTE, 1982). E, ainda que o conhecimento da relação entre esses textos não seja algo obrigatório por parte da recepção, ela tem um poder pragmático bastante considerável, a ponto de levar, por exemplo, a pesquisadora Linda Hutcheon (2011) a discutir o que ela define (a partir do próprio Genette) como "adaptações palimpsestuosas", ou seja, textos que são percebidos como adaptações de um texto anterior (as quais ela denomina "adaptações como adaptações").

Tal aspecto hipertextual, se não é fundante para a compreensão e/ou fruição de Blade Runner ou de Tetsuo, permite novos olhares e, consequentemente, novas possibilidades de análise. De um lado (e isso é pouco conhecido do grande público), o visual dos cenários do filme Blade Runner é inspirado diretamente na concepção feita pelo quadrinista Moebius para a história em quadrinhos "The Long Tomorrow"; de outro lado, a estética de Tetsuo se apropria de elementos comuns às obras ero-guro. Feita essa breve pausa metodológica, voltemo-nos finalmente a nossos objetos de análise.

\section{De "The Long Tomorrow" a Blade Runner}

"Eu vi coisas que vocês, homens, nunca acreditariam", disse o replicante Roy Batty em 1982, quando as salas de cinema receberam o lançamento de Blade Runner, de Ridley Scott. Em uma breve sinopse, o filme narra a jornada do caçador de androides Rick Deckard (responsável por localizá-los e exterminá-los), em busca de um grupo de replicantes Nexus-6, criados pela megacorporação Tyrell Corporation, que retornam à Terra em busca de mais tempo para suas vidas.

\footnotetext{
6 Diferentemente de boa parte dos pesquisadores, Genette não segue a tendência de classificar as relações entre textos como sendo "intertextuais". A intertextualidade, para Genette, seria apenas uma possibilidade, dentro de seu sistema classificatório, e não daria conta das diversas nuances que conectam os textos entre si.
} 
Questões como a realidade do corpo humano, as características necessárias para a existência do próprio ser humano e o direito à vida de seres artificiais são fios condutores da obra. Adaptação direta do livro Androides sonham com ovelhas elétricas?, 1968 e escrito por Philip K. Dick, Sammon (2017) afirma que as diferenças entre os formatos, que existem e fazem com que as obras, em até certo ponto, sejam diferentes, são apenas uma reformulação necessária de enredo entre meios. 0 livro escrito na década de 1960, em plena época da New Wave da ficção científica, não pode ser considerado cyberpunk, já que apesar de abordar a ciência como uma metáfora social, se aprofundava pouco ou nada nos temas característicos do subgênero. Dessa forma, é possível perceber, nas palavras de Sammon, as preocupações filosóficas, ecológicas e sociológicas, que se juntam à paranoia, à alienação e à esterilidade emocional do ser humano para formar o filme.

Blade Runner, com seu futuro technoir, permanece como o filme definidor da estética cyberpunk, tanto pelas construções urbanas decadentes e futuristas quanto pelas relações sociais, com a presença daquilo que Bassa e Freixas (1993) definem como o herói filosófico e questionador dos desmandos da sociedade de sua época. Acreditamos que uma das influências mais importantes na criação de Blade Runner e de suas discussões sobre cidades superlotadas, androides infiltrados e detetives caçadores foi originada em 1976 na revista francesa Métal Hurlant e, posteriormente, em 1977, na americana Heavy Metal, com a publicação de "The Long Tomorrow" por Moebius e Dan O'Bannon (SAMMON, 2017).

0 quadrinho lançado em duas partes na revista americana apresenta "uma paródia7 de filme noir/detetive estrelada por Pete Club", mostrando uma "detalhada cidade futurística, cidade essa que hoje pode ser reconhecida como tendo uma grande influência na densidade gráfica de Blade Runner" (SAMMON, 2017, p.83), conforme visto nas figuras 1 e $2^{8}$.

Figura 1- Detalhe da primeira página da HQ "The Long Tomorrow"

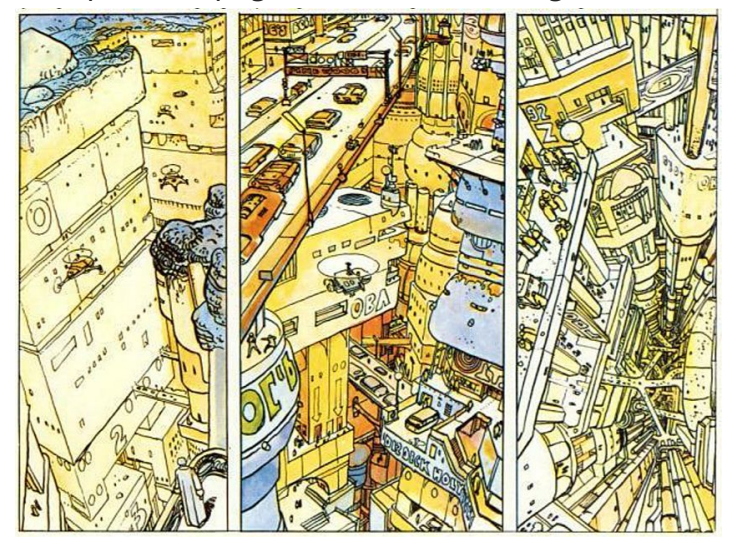

Fonte: Moebius; O'Bannon (1989).

\footnotetext{
7 Apesar de escapar ao âmbito deste artigo, particularmente consideramos "The Long Tomorrow" narrativamente como um pastiche de filme noir (ou de romances hard boiled), e não necessariamente uma paródia.

${ }^{8}$ Há também menções a influências visuais do quadro Nighthawks (1942), de Edward Hooper.
} 
Figura 2 - Cena do filme Blade Runner

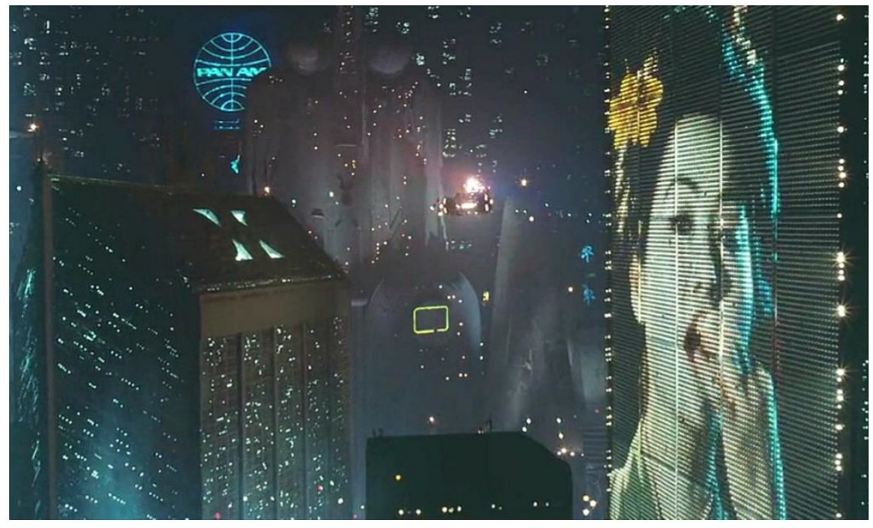

Fonte: Blade Runner (1982)

As temáticas que foram capturadas através dessas histórias podem ser pontuadas em três níveis: 1) a narrativa technoir apropriada para o filme de Ridley Scott, conforme algumas representações visuais de tipos de personagens comuns nos filmes noir (norte-americanos em geral), como o detetive e a femme fatale ${ }^{9}$, (figuras 3 e 4); 2) a cidade cyberpunk apropriada para uma Los Angeles escura e permanentemente chuvosa; e 3) o corpo como figura central das histórias, o qual é utilizado como modo de diferenciação entre humanos e alienígenas.

Figura 3-Humphrey Bogart em cena de The Maltese Falcon e Harrison Ford em Blade Runner

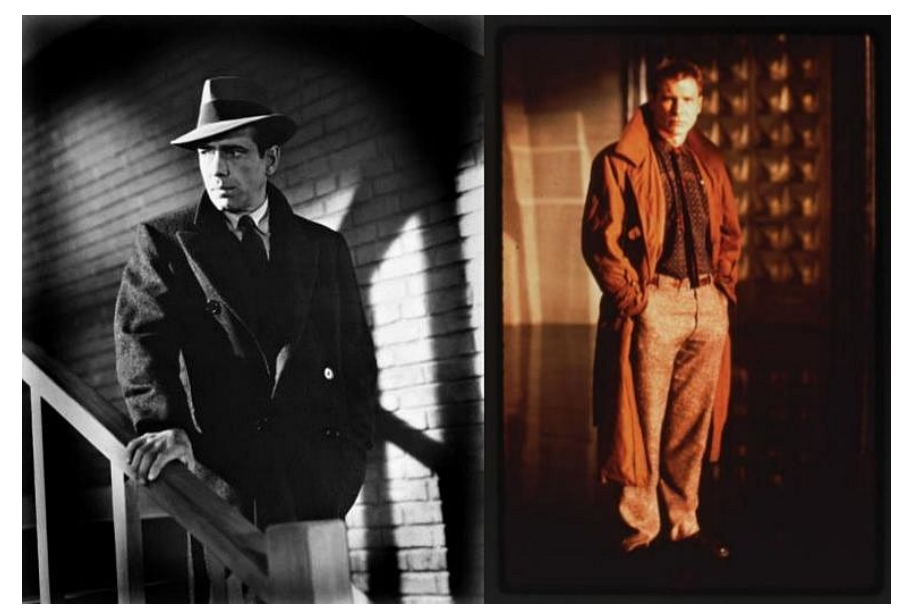

Fonte: O Falcão Maltês (1941); Blade Runner (1982).

\footnotetext{
${ }^{9} \mathrm{~A}$ femme fatale continua sendo um tipo de personagem atualizado até os dias de hoje: basta pensarmos, por exemplo, no robô Ava, interpretado por Alicia Vikander no filme Ex_Machina: Instinto Artificial (2014).
} 
Figura 4 - Ella Raines em cena de A Dama Fantasma e Sean Young em Blade Runner.
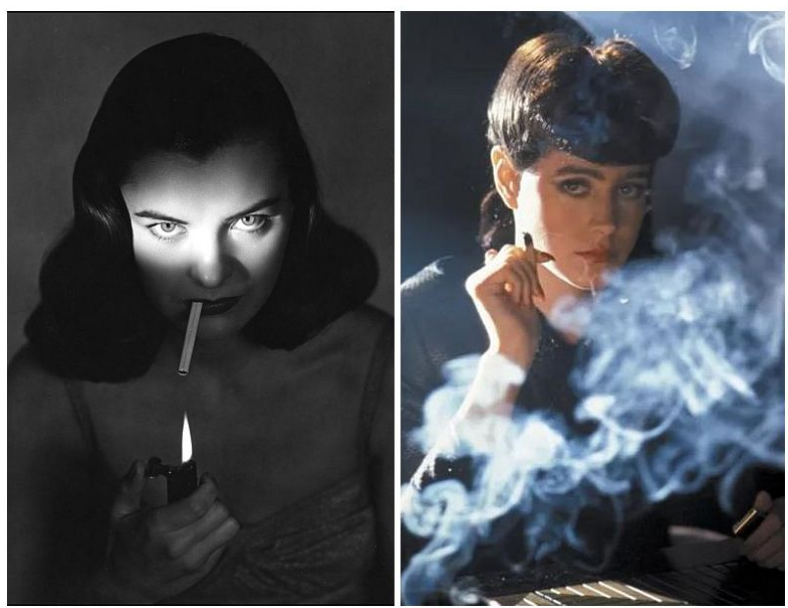

Fonte: A Dama Fantasma (1944); Blade Runner (1982).

Sobre a primeira temática, o policial com seus dilemas filosóficos é figura central no technoir. Na medida em que "The Long Tomorrow" (lembremos, um pastiche ${ }^{10}$ de noir que se passa num futuro distante) trabalha com seu personagem Pete Club (figura 5) à procura de uma alienígena fugitiva, Blade Runner apropria-se desses componentes narrativos e coloca Deckard à procura de um replicante - que, numa concepção-limite, é também um alienígena - numa Los Angeles nublada; assim, Blade Runner se apropria de elementos de "The Long Tomorrow" que, por sua vez, se apropria (em forma de pastiche), de outros aspectos a partir do universo de elementos narrativos criados tanto pelos romances hard boiled (Dashiell Hammett, Raymond Chandler) quanto pelos filmes noir não apenas norte-americanos, mas também franceses ${ }^{11}$, por exemplo. Assim, (o hipertexto) Blade Runner pode sobreviver sem (o hipotexto) "The Long Tomorrow", mas conhecer a ambos permite, dentre outras coisas, perceber tanto como ambos estavam à frente de seu tempo quanto como apresentam traços cyberpunks.

\footnotetext{
${ }^{10}$ Apesar da indumentária desenhada por Moebius para Pete Club reforçar esse aspecto paródico, encontramos outros elementos narrativos clássicos do filme noir em "The Long Tomorrow", como as falas em off do detetive, localizadas nos recordatórios da história.

${ }^{11}$ Entre alguns cineastas franceses que realizaram filmes de estética noir, estão Jules Dassin, Henri-Georges Clouzot, Julien Duvivier, Jean-Pierre Melville e Georges Lautner.
}

Memorare, Tubarão, v. 8, n. 1, jan./jun. 2021. ISSN: 2358-0593 
Figura 5-Personagem do detetive Pete Club, desenhado por Moebius para a $\mathrm{HO}$ "The Long Tomorrow"

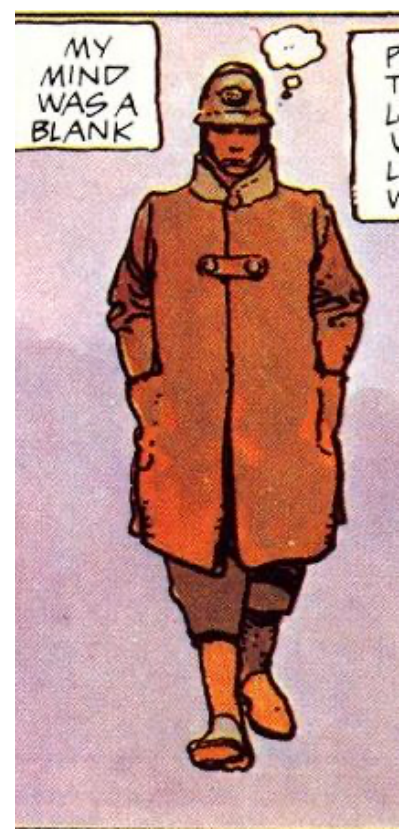

Fonte: Moebius; O’Bannon (1989).

A cidade cyberpunk, que também é uma forma de pensar esse subgênero, está em consonância com o que Harvey (2010) propõe ao falar sobre o pluralismo de mundos que existem na ficção pós-moderna, em que espaços inadequados entre si são justapostos uns aos outros, desaparecendo o mistério central da história e adicionando, dessa forma, questionamentos sobre em qual mundo se está inserido e o que se deve fazer nele. Conforme explica Amaral, a cidade aparece aqui tanto como parque temático quanto como simulação, combinando símbolos da era espacial de alta tecnologia com a visão vitoriana do crescimento desordenado e não planejado. Ela aparece a maior parte do tempo como uma entidade negativa, espaço escuro e superpovoado, quebrado por formas de néon e estruturas corporativas (AMARAL, 2006, p.65). Se antes as relações eram determinadas e as narrativas que nos formavam socialmente eram confiáveis por sua pretensa duração e infalibilidade universal, agora temos "a fragmentação, a indeterminação e a intensa desconfiança de todos os discursos universais ou 'totalizantes'” (HARVEY, 2010, p.19).

Nesse sentido, o cyberpunk oferece esse caráter mutável, o que nos leva a pensar que enxergar o presente como indeterminado e fragmentado acarreta aos seus personagens a busca por uma redefinição dos espaços em que se encontram, transformando as cidades em centros caóticos incontroláveis, por oferecerem, como descreve Harvey (2010, p. 49), pouca ameaça para o controle geral exercido pelas corporações.

\section{Ero-guro, mangás e Tetsuo}

A cena underground do cinema japonês também é um ambiente propício para o desenvolvimento de novas obras, tanto que em 1980, um movimento cinematográfico buscou referências na ficção científica cyberpunk para construir obras que se conectassem à cultura da velocidade (DE KERCKHOVE, 1995). Relacionando-se com a tecnologia 
invasiva, percebeu-se a possibilidade de transformação do corpo e a formação de um novo humano. Além de relativizar as fronteiras entre o ser humano e as máquinas, na contemporaneidade, as relações do corpo com os implantes e com as alterações tornam-se um hábito, tendo reflexos não apenas no âmbito psicológico, mas também erógeno: as alterações de nosso corpo possibilitam novas maneiras de erotização corporal, através de implantes ou reparos.

0 belo a ser buscado é o do aprimoramento, o da transformação ou o da substituição corpórea, ocasionando um belo que beira o grotesco pela presença dos implantes ou das mutações, como podemos ver nas figuras 6 e 7, que ilustram respectivamente o apego ao erótico e à alteração do corpo humano (particularmente, citamos a obra de Shintaro Kago, e seu mangá Dementia 21, figura 8).

Figura 6 - Ilustração de Takato Yamamoto para Salomé, de Oscar Wilde.

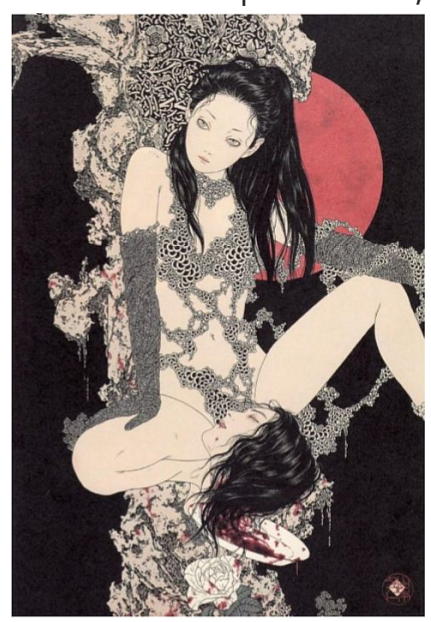

Fonte: Yamamoto (2019).

Figura 7 - Ilustração de Shintaro Kago para o álbum Nanoångström, da banda britânica de metal Bast.

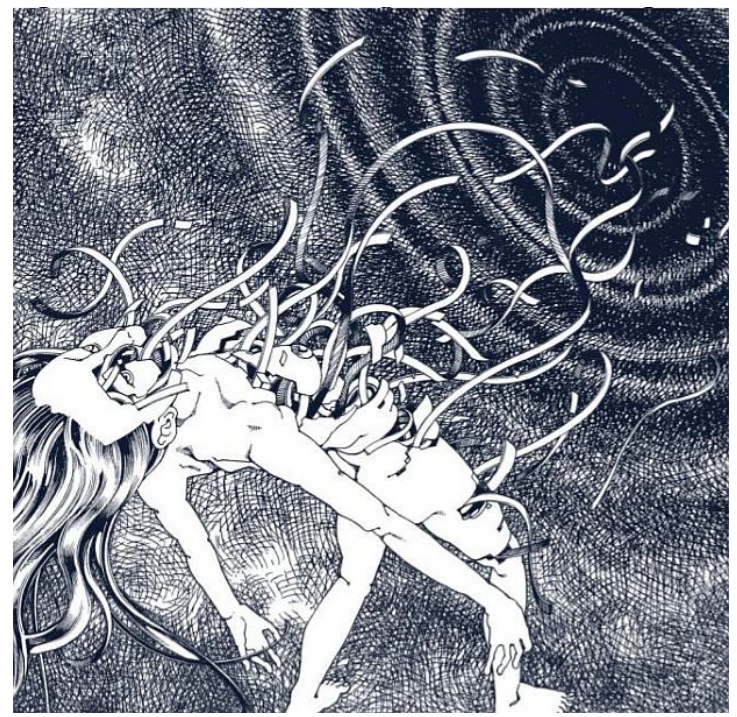

Fonte: Kago (2019). 
Figura 8 - Vinhetas do mangá Dementia 21, de Shintaro Kago.

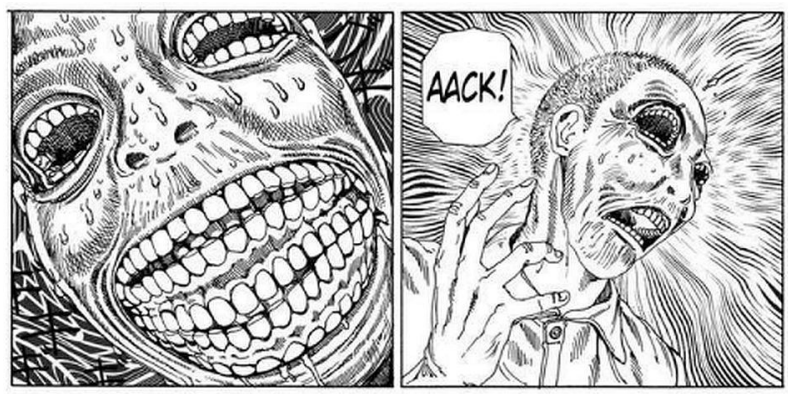

Fonte: Kago (2020).

Essa conexão entre erótico e grotesco faz parte do pensamento sobre o corpo como forma de alcançar essa transformação, e tem um importante desenvolvimento no Japão desde a década de 1930, quando assuntos eróticos, grotescos (grotesque/gurotesuku) e sem sentido (nonsense/nasensu) circulavam na cultura do Império japonês. Inicialmente, "ero-guro-nasensu", o estranho e o grotesco podiam ser vistos tanto em ilustrações quanto nos movimentos artísticos e literários japoneses. Com o passar do tempo, a abreviação para as imagens e literaturas sobre fantasias eróticas sombrias, combinadas com atitudes e objetos abjetos, tornou-se apenas "ero-guro" (BRANDÃO, 2015, p.2).

Apesar do ero-guro ser intrinsicamente ligado à militarização japonesa no período da II Guerra Mundial, houve "uma intensa exploração sexual, hedonista e sensacionalista de tudo que fosse anormal e tabu, refletindo não apenas desejos sensuais recémdescobertos, mas uma erupção de mudanças políticas extremas" entre civis e militares (BRANDÃO, 2015, p. 2). Após a guerra e a derrota do império japonês, essa estética foi se incorporando à cultura japonesa, cujos principais vetores dessa divulgação foram os animes, os mangás e o cinema, nos quais o erótico e o grotesco voltaram-se às questões da dualidade corpo/máquina. Essa mudança ocorreu justamente no pósguerra, como acredita Sato (2004), ao afirmar que as narrativas do pósguerra foram essenciais para que a cultura pop japonesa começasse a ver as tecnologias como um fator não só de destruição do seu território, mas também de criação de um novo ser humano.

A mentalidade cibernética que condiciona essas narrativas fantásticas do pós-guerra é, na verdade, uma aceitação ativa e quase torturante de partes de máquinas na carne humana, o que impulsiona a identidade japonesa para a sobrevivência e a vitória do pós-guerra sobre as principais nações por meio da incorporação radical da tecnologia (SATO, 2004, p. 335). Segundo Amaral (2006), essa problematização é fundamental para a compreensão do cyberpunk pelos japoneses, que não seguem a mesma forma de compreensão dos norteamericanos.

O mundo do cyberpunk japonês no cinema afasta-se das noções estabelecidas pelo Ocidente (cultura hacker dos invasores do ciberespaço; tecnologias onipresentes de vigilância e controle; conglomerados dominantes). Aqui há uma representação de humanos transformando-se em máquinas em meio a metrópoles deterioradas e pós-industriais, como se estivessem em um pesadelo de violência e 
rebeldia. De acordo com Brown (2010), o cyberpunk japonês caracteriza-se pela atitude e não pelo conceito, ou seja: é demasiado punk em relação ao americano, no qual é a parte cyber que toma dianteira. Isso pode ser visto quando compararmos Tetsuo com Blade Runner, que suaviza a interação carne-metal, optando pela diferenciação entre o humano e o replicante, enquanto a obra japonesa propõe uma relação do limite do corpo-metal.

Filmado em $16 \mathrm{~mm}$ e preto e branco, podemos dizer que Tetsuo é a obra máxima de Shinya Tsukamoto, assim como foi responsável pelo surgimento do cyberpunk naquele país. Com características de baixo orçamento na produção, o diretor apresenta uma obra experimental em hipervelocidade que alia os elementos do surrealismo de David Lynch e o horror corporal de David Cronenberg (BROWN, 2010), criando algo único. Na história, seguimos um homem, chamado apenas de "Yatsu"12, o qual após cortar sua perna, insere uma barra de metal no ferimento, até que surjam as primeiras larvas no local. Não nos é informado o motivo dessa punição - ou prazer. Após isso, ele entra em pânico com o agravamento da dor e sai na rua, acaba sendo atropelado pelo carro de um trabalhador japonês - o salaryman - e sua namorada que estava de carona. Yatsu persegue o salaryman com o objetivo específico de transformá-lo em um homem de metal, o que acontece ao longo do filme, quando o perseguido vai ganhando partes de metal pelo corpo (figuras 9 e 10). Assim, aquilo que na arte ero-guro, em geral é percebido apenas potencialmente como um (hipo)texto descritivo, em Tetsuo ganha narratividade; e, ainda que não pareça haver explicações aparentemente lógicas para as transformações, elas existem. Aqui, neste caso e dentro da lógica cultural japonesa, antes e depois (narrativamente falando), os motivos para tais transformações são irrelevantes, seja na arte ero-guro, seja em Tetsuo.

Figura 9-Cena de Tetsuo na qual o personagem salaryman percebe o início de sua transformação.

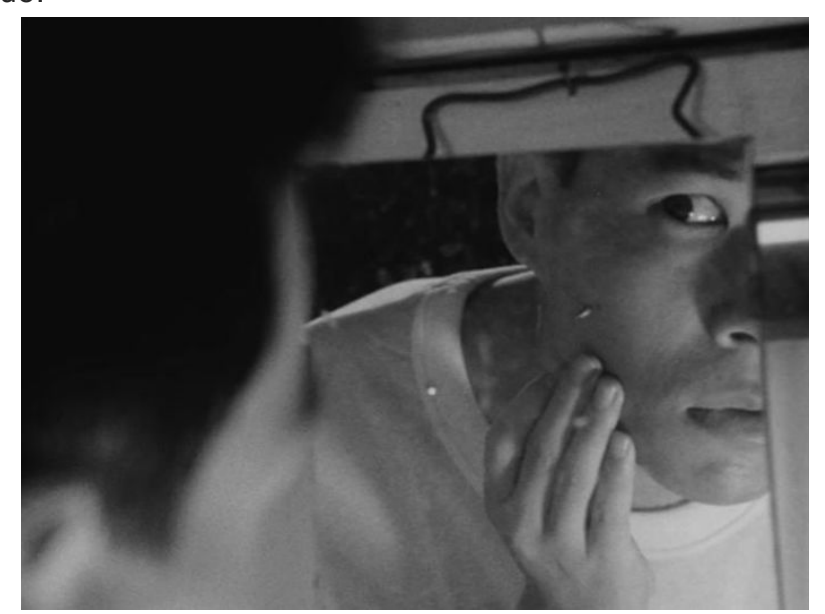

Fonte: Tetsuo (1989)

12 Pronome japonês que pode significar “cara”, "guy”, e é considerado, na cultura japonesa, entre muito informal e pejorativo. 
Figura 10 - Cena de Tetsuo na qual o personagem salaryman já tem o metal incorporado ao próprio corpo.

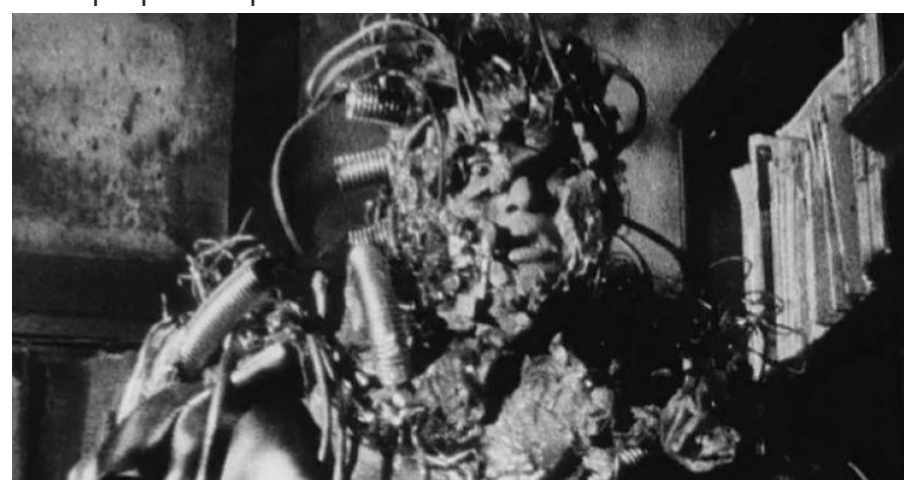

Fonte: Tetsuo (1989).

É possível identificar ainda uma temática bastante pertinente ao desenvolvimento do cyberpunk no Japão, que é o limite da junção da carne ao metal como um dos últimos estágios do corpo pós-humano (BROWN, 2010). Ao penetrar a barra de metal na perna, as mudanças no corpo de Yatsu são resultado da sua vontade própria de se fundir à tecnologia. Sua fusão e transformação em outro corpo sucedem até o encontro com o salaryman, onde um novo mundo é criado: após sua metamorfose completa em um ser de metal, os dois pós-humanos tornam-se uma nova criatura orgânica e de metal ("tetsuo") ${ }^{13}$, com poder para criar um mundo metálico e então dizimá-lo (figura 11). A ojeriza pelo corpo humano, representada pela destruição transcendental do ser humano, e a sua recriação unida à tecnologia são refletidas pelo prazer dos personagens, pois já não há mais dois seres humanos ali, e sim um corpo pós-humano. 0 ápice da estética ero-guro é atingido filmicamente aqui.

Figura 11 - Cena de Tetsuo na qual os personagens Yatsu e salaryman aparecem como um só corpo, feito de carne e metal

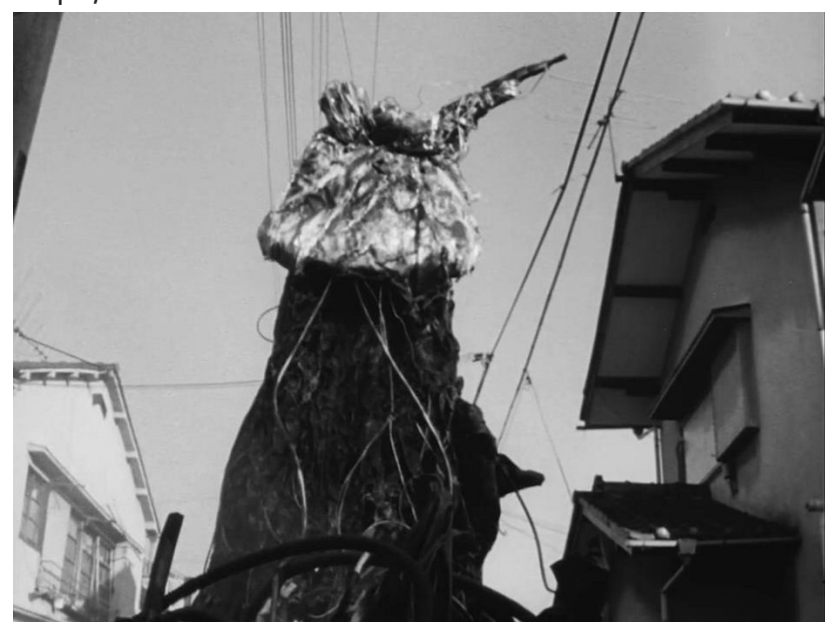

Fonte: Tetsuo (1989).

Por fim, percebemos a predominância pela transformação dos corpos: recorrendo frequentemente à potência imagética dos mangás, conforme afirma Novielli, a carne funde-se com o metal constantemente;

${ }^{13}$ Cumpre lembrar que, em japonês, a palavra "tetsuo" é um substantivo masculino que tanto pode significar "filósofo" quanto "homem de ferro". 
as apocalípticas devastações cyberpunks e anormais jorros de sangue, piercings e violências contra o corpo a fim de defini-lo, além de geométricas e metálicas representações urbanas (ainda mais bem visualizadas por meio dos tons de branco de Tetsuo), retomam incansavelmente a ideia de que também exista a possibilidade de perder a vida numa sociedade que - sustenta a autora - se julga invulnerável, como a sociedade japonesa (NOVIELLI, 2007, p.293).

\section{Considerações finais}

Partimos nessa investigação com o objetivo de descobrir quais as diferenças entre os cyberpunks ocidental e oriental, olhando especificamente, no âmbito deste artigo, para algumas produções americanas e japonesas. Ao término parcial desta jornada, é possível aferir que as diferenças que podem separar essas duas culturas são as mesmas que as unem como um subgênero. Blade Runner com seu ritmo lento e cadenciado, e momentos "filosóficos existencialistas", contrasta, de fato, com a hipervelocidade de Tetsuo e suas imagens unidas em uma narrativa pós-moderna de transformação e transcendência do corpo humano. Mas o que verificamos nesse artigo foi a presença anterior dessas discussões em outras obras, em que tanto a rebeldia quanto a investigação policial já se faziam presentes, assim como a naturalidade com a qual um corpo perde sua carnicidade ao juntar-se com metal ou afins.

Levando em consideração que cada um desses objetos apresenta matrizes textuais (culturais) distintas, isso nos leva a perceber que não há apenas uma forma de se entender o cyberpunk no mundo. 0 mais intrigante disso é que os temas centrais também mudam nossa percepção sobre o tema, e isso faz diferença quando trabalhamos com filmes e imagens. Por exemplo, quando Blade Runner se apropria narrativamente do que é trabalhado em "The Long Tomorrow", faz isso levando em conta a arquitetura opressora da cidade, faz isso com o estilo narrativo technoir, faz isso com o enredo, mas também apresenta uma interpretação de corpo característico, o qual pode ser melhorado a partir de próteses. Movimento transtextual (estético-artístico) similar ocorre em Tetsuo, que se apropria de todo o ethos criado pelo ero-guronansensu e pela estética dos mangás para se tornar o principal expoente do cyberpunk no Japão, o qual é permeado pela violência, pelo erotismo e pela mutação exacerbada dos corpos, levando até a sua eliminação.

Mas também percebemos outro aspecto importante: a existência de diferentes formas de interpretar o corpo: se, de um lado, o cyberpunk norte-americano parece ter em mente elementos narrativos clássicos do cinema noir e dos filmes e quadrinhos de ficção científica, nos quais o corpo humano é quase sempre colocado em confronto com o corpo artificial, de outro lado, o cyberpunk japonês parece seguir numa direção oposta, na qual os corpos, sejam eles humanos ou artificiais, podem se fundir (por mais estranhos e bizarros que eles possam parecer).

Assim, certas matrizes textuais acabam sendo importantes para a delimitação conceitual do cyberpunk nas culturas norte-americana e japonesa e, por extensão, nas cultuas ocidental e oriental. Por conta dessa tradição textual, na qual o corpo acaba sendo o locus onde essas diferenças culturais mais estão manifestas, uma nova indagação surge:

Memorare, Tubarão, v. 8, n. 1, jan./jun. 2021. ISSN: 2358-0593 
por que os corpos tendem a ser representados de formas tão distintas nessas culturas? Quais são as distopias do corpo que ambas as culturas oferecem em seus produtos midiáticos? Essa é uma indagação para um momento futuro, apesar dessa ideia parecer soar levemente estranha...

\section{Referências}

A DAMA Fantasma. Direção de Robert Siodmak. Produção de Joan Harrison. Intérpretes: Franchot Tone, Ella Raines, Alan Curtis, Aurora Miranda. Roteiro: Bernard C. Schoenfeld, Cornell Woolrich: [s.i], 1944. (87 min.), DVD, son., color. Legendado.

AMARAL, A. Visões Perigosas: uma arque-genealogia do cyberpunk: do romantismo gótico às subculturas. Porto Alegre: Sulina, 2006.

BASSA, J.; FREIXAS, R. El Cine de Ciencia Ficción: una aproximación. Barcelona: Paidós, 1993.

BLADE Runner. Direção de Ridley Scott. Produção de Michael Deeley. Intérpretes: Harrison Ford, Rutger Hauer, Sean Young Edward, James Olmos, Daryl Hannah. Roteiro: Hampton Fancher, David Peoples. Música: Vangelis. [s.i]: The Ladd Company, Shaw Brothers, Blade Runner Partnership, 1982. (117 min.), DVD, son., color. Legendado.

BORGES, P. M. Mangás: estética bidimensional e deslocamentos culturais. São Paulo: Intermeios, 2016.

BRANDÃO, V. G. “Ero-Guru: o corpo abjeto na erótica e grotesca literatura de Suehiro Maruo". In: Congresso de Literatura Fantástica de Pernambuco, 5, Recife. UFPE. pp. 1-13, 2015. Disponível em: http://www.academia.edu/33064442/EroGuru_o_corpo_abjeto_na_erotica_e_grotesca_literatura_de_Suehiro_Maruo. Acesso em: 20 nov. 2018.

BROWN, S. T. Tokyo Cyberpunk: posthumanism in Japanese visual culture. New York: Palgrave Macmillan, 2010.

ECO, U. “Os Mundos da Ficção Científica”. In: ECO, U. Sobre os Espelhos e Outros Ensaios. Rio de Janeiro: Nova Fronteira, 1989, p. 166-172.

FALCÃO Maltês, O. Direção: John Huston. Warner Home Video, 1941. 1 DVD (100 min.)

GENETTE, G. Palimpsestes: la littérature au second degré. Paris: Seuil, 1982.

GOMES M., M.; LONDERO, Rodolfo Rorato; \& NASCIMENTO, M. A.. “McLuhan e Neuromancer: aldeia global e outros conceitos no imaginário cyberpunk".

Revista Famecos 16, v. 38, p. 111-117, 2009.

HAN, B. C. Sociedade do Cansaço. Vozes, Petrópolis, 2017.

HARVEY, D. A Condição Pós-moderna: uma pesquisa sobre as origens da mudança cultural. São Paulo: Loyola, 2010.

HUTCHEON, L. Uma Teoria da Adaptação. Florianópolis: Editora UFSC, 2011. 
JAMESON, F. Espaço e Imagem: teorias do pós-moderno e outros ensaios de Fredric Jameson. Organização e tradução: Ana Lúcia Almeida Gazolla. Rio de Janeiro: Editora UFRJ / MEC-INEP, 1994.

KAGO, S. Nanoångtröm. [S.I.]: Tóquio, 2019.

KAGO, S. Dementia 21. São Paulo: Todavia, 2020.

KATO, S. Tempo e Espaço na Cultura Japonesa. São Paulo: Estação Liberdade, 2012.

KERCKHOVE, D. The Skin of Culture: investigate the new electronic reality. Toronto: Somerville House, 1995.

LEMOS, A. Cibercultura: tecnologia e vida social na cultura contemporânea. Porto Alegre: Sulina, 2002.

MATTHEW, R. Japanese Science Fiction: a view of a changing society. New York: Routledge and Nissan Institute of Japanese Studies, 2005.

MOEBIUS; O'BANNON, D. "The Long Tomorrow". In Heavy Metal Magazine. n. 5, v.1, Massachusetts: HM Communications, Inc, 1977.

NOVIELLI, M. R. História do Cinema Japonês. Brasília: Editora Universidade de Brasília, 2007.

ROBERTS, A. A verdadeira história da ficção científica: do preconceito à conquista das massas. São Paulo: Seoman, 2018.

SAMMON, P. M. Future Noir: the making of Blade Runner. Nova York: Dey St, 2017.

SATO, K. "How information technology has (not) changed feminism and Japanism: cyberpunk in the Japanese context". Comparative Literature Studies, 41 (3), pp. 335-355, 2004.

TETSUO. Direção de Shinya Tsukamoto. Produção de Shinya Tsukamoto. Realização de Shinya Tsukamoto. Intérpretes: Tomorowo Taguchi, Kei Fujiwara, Shinya Tsukamoto. Roteiro: Shinya Tsukamoto. Música: Chu Ishikawa. Tóquio: Shinya Tsukamoto, 1989. (67 min.), DVD, son., P\&B. Legendado.

YAMAMOTO, Takato. ARTIST OF THE MONTH: TAKATO YAMAMOTO. [S.I.]: Muudy Colors, 2019. Disponível em: http://www.muddycolors.com/2019/05/artistof-the-month-takato-yamamoto. Acesso em 26. abr. 2020.

Artigo enviado em: 05/05/2021. Aprovado em: 21/06/2021. 